\title{
German-African Cooperation in Global Health: The Role of Social Sciences in Higher Education Degree Studies, Training, and Research Projects ${ }^{1}$
}

\begin{abstract}
Global health has gained in importance in Germany in recent years and became visible quite recently both at German institutions of health education and research and on the political agenda of various ministries. What exactly is meant by global health remains vague. In particular, the inter- and transnational conditions and effects of health and disease outbreaks are seen as specific to global health, which requires an inter- and transdisciplinary perspective that includes social science aspects and methods.

Africa has also moved into the focus of Germany's international cooperation policies in recent years. Due to the lack of medical personnel in Africa and also in Germany, the education and training of medical personnel in Africa plays an important role in German-African cooperation in the health sector. Cooperation in the training of health personnel can have primarily economic reasons, but may also follow other interests, such as aid, exchange and cultural diplomacy for the German and African side. While the training of medical personnel is primarily clinically oriented, at least in Germany there is a strong tendency towards less clinically oriented training and study programmes in the health sector. The inclusion of social sciences in the training of physicians and nurses in the curricula is also mandatory. However, the integration of the social sciences is only reflected to a limited extent in the institutional funding of German-African health projects, although it can be assumed that these aspects also play an important role in the training of health personnel in Africa. Greater integration of social sciences into German global health education and research could contribute to this also being incorporated into German-African cooperation. This way, social scientific global health research in Germany and Africa would help to analyse determinants of health at the meta-level so that they can be taken into account in national and international strategies and laws and may be implemented in health projects.
\end{abstract}

Keywords: Global health, health professionals, social sciences, health education, international relations

\begin{abstract}
Zusammenfassung
Global Health hat in den letzten Jahren in Deutschland an Bedeutung gewonnen und erscheint seit kurzem sowohl an Institutionen der Gesundheitsbildung und -forschung als auch auf der politischen Agenda unterschiedlicher Ministerien. Was genau unter Global Health verstanden wird, bleibt allerdings bisher recht vage. Jedoch werden interund transnationale Bedingungen und Auswirkungen von Gesundheit und Krankheitsausbrüchen als Spezifikum von Global Health betont, was eine inter- und transdisziplinäre Perspektive erfordert, die insbesondere sozialwissenschaftliche Aspekte und Methoden einbezieht.

Afrika ist in den letzten Jahren ebenfalls in den Fokus der internationalen Zusammenarbeit Deutschlands gerückt. In der deutsch-afrikanischen Kooperation im Gesundheitsbereich spielen, aufgrund des Mangels an medizinischem Personal in Afrika und auch in Deutschland, die Ausbildung und das Training von medizinischem Personal in Afrika eine wichtige Rolle. Die Kooperation in der Ausbildung von Gesundheitspersonal kann primär wirtschaftliche Gründe haben, aber ebenso andere Formen der Kooperation, wie Hilfe, Austausch und kulturelle Diplomatie für die deutsche und die afrikanische Seite bedeuten. Während die Ausbildung medizinischen Personals primär klinisch orientiert ist, ist zumindest in Deutschland eine starke Tendenz zu weniger klinisch orientierten Ausbildungs- und Studiengängen im Gesundheitsbereich zu verzeichnen. Ebenso ist die Einbindung von Sozialwissenschaften in die Ausbildung von Ärzten und Pflegekräften in den Curricula vorgeschrieben. Eine solche Einbindung von Sozialwissenschaften spiegelt sich in der institutionellen Förderung deutsch-afrikanischer Gesundheitsvorhaben allerdings nicht wider, obwohl davon auszugehen ist, dass diese Aspekte auch für die Ausbildung von Gesundheitspersonal in Afrika eine wichtige Rolle spielen. Eine stärkere Integration von Sozialwissenschaften in die deutsche Global-Health-Ausbildung und -Forschung könnte dazu beitragen, diese auch in die deutsch-afrikanischen Kooperationen einzubringen. Sozialwissenschaftliche Global-Health-Forschung in Deutschland und Afrika würde so dazu beitragen, Determinanten von Gesundheit auf Metaebene zu analysieren, so dass diese in nationalen und internationalen Strategien und Gesetzen berücksichtigt und in Gesundheitsvorhaben umgesetzt werden können.
\end{abstract}

Schlüsselwörter: Global Health, Gesundheitspersonal, Sozialwissenschaften, Gesundheitsbildung, internationale Beziehungen 


\section{Definitions of global health}

A common question and matter of discussion is: what is meant by global health? While not only one definition exists, there seems to be a common understanding that global health is very much related to globalization and international relations and their interconnections to health on a local, regional and national level. According to Koplan et al. (2009, p. 1995) "global health is an area for study, research, and practice that places a priority on improving health and achieving equity in health for all people worldwide", while Kickbusch (2006, p. 561) refers to it as "those health issues that transcend national boundaries and governments and call for actions on the global forces that determine the health of people". In a recent qualitative study among German medical teaching personnel on the definition of global health (Havemann \& Bösner, 2018), global health was defined as an umbrella term for public health, international health and tropical medicine. The inter- and transdisciplinarity of global health education and research was highlighted and the authors concluded that a continuous challenge of this umbrella term would be to find a fine-tuned balance between a too narrow and a too broad definition of global health.

Even though global health considers international and transnational aspects of health and focuses very much on health in low-income countries, it must be said, that so far education and research in global health is mainly conducted in high-income countries.

\section{The political background: The German global health \& Africa strategy}

In the last decade both topics, global health as well as a special focus on Africa, have gained in importance in German Higher Education and Development Cooperation policies.

The first German global health strategy was adapted and published by the Ministry of Health in the year 2013. It emphasized in its introduction: "Global health issues are closely related to numerous other fields of policy such as development, security, trade, economics, human rights, food, agriculture, research, employment, education, migration, environmental and climate protection as well as humanitarian aid. Against this background, solutions that reach across individual sectors are needed. Consequently, questions of global health are now no longer just discussed among experts from the field of health within the context of professional organisations responsible for health." (BMG, 2013, p. 2).

Global health received major public attention in Germany with the Ebola outbreak in Western Africa in 2014/2015. Since the German G-7 and G-20 presidency in 2014/2015 and 2017, respectively, it has been an increasingly important topic on the German political agenda. Currently, the German Ministry of Health is developing a new global health strategy in cooperation with several partners from civil society, industry and academia that will be implemented by the end of 2019. In February 2019 the German Ministry for Economic Cooperation and Development published a strategy paper "Global health - an investment in the future" (BMZ, 2019), which mainly summarizes ongoing health activities of the BMZ. It focuses on health systems, prevention, healthy start in life including sexual education and family planning, prevention of pandemics, global financing mechanisms and multilateral cooperation and digitalization. However, even though Germany has increased its efforts and almost doubled its global health spending in the past 10 years, it is still not achieving the $0,1 \%$ of gross national income (GNI) towards official development assistance for health, as recommended by the World Health Organisation (Kickbusch et. al, 2017).

Also recently, Africa became a focus of the German and the European Union's foreign policies. The German BMZ presented its Marshall Plan for Africa for the first time in 2016 also (highlighting) the need for partnership and economic cooperation between the European Union and Africa. One of four fundamentals of this plan is related to the topic health, education and social security. The lack of infrastructure, facilities, equipment and especially of skilled professionals and administrative staff to provide education and basic health care services was recognised. On the German side, among others, intensified economic cooperation with Africa and increasing numbers of scholarships with the goal of mutual learning and more initiatives for the training of skilled health workers and training on family planning and maternal health were requested (BMZ, 2017).

\section{Health care professionals in Africa and the cooperation scenery with Germany}

In 2015 the United Nations agreed on the Sustainable Development Goals (SDGs) that since then have shaped the international Agenda 2030 and national implementations of this agenda. It should be noted that the SDGs of this UN Agenda 2030 have also been recognised as major political guidelines for political debates and planning in Germany by governmental as well as non-governmental actors such as federal ministries, governmental agencies, churches, foundations, enterprises, academia and others, which means, they have also entered German-African development cooperation policies including higher education and research.

The SDGs encompass 17 goals with 169 indicators to monitor and evaluate their progress till 2030. The overall aim of the SDGs is to make progress on all goals and to recognise their interdependency to achieve sustainable development. SDG goal 3 is directed towards "good health and wellbeing", but progress in almost all other SDGs would also have positive direct or indirect impact on health and wellbeing. The strong relation between health (SDG 3) and education (SDG 4) is even highlighted in one of the health goal's targets: "3.c: Substantially increase health financing and the recruitment, development, training and retention of the health workforce in developing countries, especially in least developed countries and small island developing States".

The SDG 3 also focuses on education and work conditions of health professionals and is measured with the indicator 3.c.1 "Health worker density and distribution". But comparing data on national health workforce might lead to perplexities. While the information about the density of health care workers differ by source (WHO, 2018; Willcox et al., 2015), a critical shortage (defined as $<2.2$ health care workers/1000 populations) exists in almost all sub-Saharan African countries. There is also a low number of medical schools in most sub-Saharan African countries. Among the 15 countries with the lowest density of medical schools (0.06-0.11 schools per million), 14 are located in sub-Saharan Africa (Duvivier et al., 2014). 
However, not only the lack of capacity to educate and train health workers counts for the low number of health workers. At the same time in most countries a large number of unemployed, trained and skilled health workers exists; health workers with skills unsuited for the needs of their countries or communities because the focus has been on clinical training and not on public health. Furthermore, an internal maldistribution of health workers with most of them located in urban areas exists. Other problems are poor working conditions, including unsafe workplaces, inadequate compensation and incentives, and insufficient or no career opportunities.

Trained and skilled health workers often move from the public to the private sector or migrate from the so-called developing to more developed countries, widely known as brain drain. While there is a shortage of health professionals in Afri$\mathrm{ca}$, at the same time Africa supplies health professionals to the developed world. For example, in Portugal in 2007, more than $25 \%$ of all foreign trained doctors were from Africa (Connel et al., 2007). Among the working medical doctors in Germany in $2017,11,8 \%$ had a foreign nationality and of these $6,8 \%$ were from Africa (Bundesärztekammer, 2017).

The emigration of other health professionals such as nurses also contributes to the shortcoming of health professionals in Africa. For instance, Germany has a shortage of health professionals, especially nurses. Therefore, the German Federal Employment Agency's International Placement Services (ZAV) and the Deutsche Gesellschaft für Internationale Zusammenarbeit (GIZ) GmbH have for instance set up a joint project to bring well-qualified nurses from Serbia, Bosnia and Herzegovina, the Philippines and Tunisia to Germany (GIZ, 2018). The project is said to have advantages for all three sides: Nurses are able to live and work in Germany under fair conditions. At the same time, unemployment is reduced in their countries of origin, and these countries benefit from migrants' financial remittances. In Germany, meanwhile, hospitals and care facilities are able to fill their vacancies with qualified staff from abroad. While this initiative is not targeted at countries in sub-Saharan Africa (as yet), it is likely that migration of health professionals from sub-Saharan Africa might increase in future under similar conditions.

But even if attracting health professionals from Africa might not be envisaged primarily by the German government, the education and training of health care professionals in Africa itself is a promising investment strategy (World Bank, 2008). The involvement of the medical industry and the attractiveness for private investments in Africa is in line with the German Marshallplan with Africa. As described by Adick in this journal edition (Adick, 2019), cooperation has many facets. In her analysis, she distinguishes between the types of Aid (understood as donations to recipients in need), Exchange (meaning formats of 'connections' that are encompassing 'true' vice versa cooperation), Cultural Diplomacy (which stands for educational transfer across borders as part of the official foreign policy of a given country) and Trade (considered to be entrepreneurial types of international educational transfer). While a World Bank publication, including examples of successful business models in medical and nursing education focuses on trade, some German global health projects might also fall into this category which can be found in motives like the „Qualification of African students (physicians, engineers, etc.) in the context of pilot seminars and workshops at local colleges; so that they can also be introduced to German products and services." (BMWi, 2017, p. 4). But other programs of global health cooperation of Germany as well as of other donor countries might also encompass non-economical motives such as the ones (aid, exchange, or cultural diplomacy) depicted in Adick (2019). For instance, the Hospital Partnerships Programme of the BMZ (http://www. klinikpartnerschaften.de/en) focuses on „exchange“ between peer-to-peer partnerships and on mutual learning and emphasizes "equal” German-African partnerships while a stronger focus on „aid“ can be found in the Product Development Partnerships (https://www.gesundheitsforschung-bmbf.de/en/prod uct-developmentpartnerships-pdps-8692.php) that target diseases which disproportionately affect underserved populations and where commercial incentives are missing.

\section{Social sciences \& global health in higher education degree studies, training and research projects}

In Germany, different categories of health professionals are educated and trained on different levels, for example in form of post-secondary and technical and vocational education, and in higher education institutions such as classical Universities, but also Universities of Applied Sciences (Fachhochschulen) for which Germany is renowned. This may challenge allocating programs of cooperation between German and African partner institutions; for instance, if nurses are studying at higher education institutions receiving academic degrees in Africa while they are at present trained on non-academic levels in Germany which, however, might change in future because of the demands, to reschedule professional trainings to fit into the European Higher Education Credit Transfer System (ECTS) including the Bachelor, Master and Doctoral Degree structure.

Furthermore, the field of health professionals is manifold: next to classical professionals as medical doctors and nurses more and more new non-clinical professions and specializations are demanded on the growing health (care) market. These new professions have often broader interdisciplinary curricula that add special knowledge and skills in management, social science or ICT to the classical clinical education. It is also a question which of these new requirements and competencies are allocated to which newly defined professions and to which level of academic or non-academic education. But even in the classical medical education new knowledge and skills are needed to provide quality care in times of globalisation, digitalisation, and demographic change and to be integrated into the curricula. All this challenges the former idea of a monolithic block of purely, clinical' knowledge and teaching.

Social sciences have already entered medical training, e.g. Medical Sociology which is part of the curriculum for medical studies and also part of most public health master degrees and postgraduate courses. Social science training in health offers e.g. basics of qualitative and quantitative research methods, understanding of health inequalities and social determinants, patient centered care, and health service organization. Also, global health, that is not part of the curriculum (yet), is discussed as an important topic in medical teaching. Global health might not only be an interesting topic for medical stu- 
dents but is becoming ever more relevant with increased migration and the import of "new" diseases not common in Germany. Furthermore, students and later patients might benefit from global health programs when they include forms of exchange so that students can work in a setting with less resources and the absence of modern medical technologies. Such an experience probably makes students more patient-centered and lets them work more resource-efficiently (Frenk et al., 2010).

But even though both, social sciences and global health, have come to being recognized as important for health professionals in Germany, they are mostly taught by different professionals: social scientists with a health focus or an additional public health degree teach social science related modules, and teaching staff with a medical background, who often have an additional training in tropical diseases or public health, teach global health. Even though the interconnection of social sciences and global health has been recognized by several authors (Bozorgmehr, 2010; Havemann \& Bösner, 2018), the topic of global health is so far not yet really recognized by those social scientists who are involved in the education and training of healthcare professionals. However, a statement of an interviewee in a paper on global health among medical teachers shows that there is an opportunity for social scientists to strengthen their position in global health teaching and research in Germany: "Exactly, I think, this is a field, where we can foster aspects of social sciences within the medical training. And we can use a topic, that is actually very interesting and that allows us to reach out to students by their call it Schweitzer-motive." (one interviewee in Havemann \& Bösner, 2018, p. 9).

Those few anthropologists, political scientists, and sociologists working in the field of global health in Germany are generally not involved in the education and training of medical doctors and nurses; and therefore social science aspects are also not (yet) included in German-African cooperation programs on education and training of health professionals in Africa. This is to be regrettet, because the ongoing epidemiological transition with an increase of chronic diseases, the strong influence of social determinants on the health of the African population, and the need for prevention and quality health care in resource constraint systems increases demands for non-clinical social sciences-based knowledge among health professionals. Social science modules and training would provide skills to health professionals to take leadership for health systems management, transformation, and research in Africa.

The missing link between social sciences and global health in Germany is also reflected in the current German institutional health funding for Africa. The following examples of current health funding programs with Africa are listed and categorized by whether they are clinically, public health, or social science oriented.

\section{Mainly clinically oriented funding programmes: Bundesministerium für Bildung und Forschung; Federal Ministry of Education and Research (BMBF):}

- Product development partnerships: targets diseases which disproportionately affect underserved populations and where commercial incentives are missing, German-African cooperation possible but also open to other countries (https://www.gesundheitsforschung-bmbf.de/en/ product-development-partnerships-pdps-8692.php)

- German-African Networks for health research: five networks conduct research on high-burden diseases in Africa to enhance clinical and laboratory practices. The initiative unites researchers from 26 African institutions in 14 countries as well as 10 German partners (https://www. gesundheitsforschung-bmbf.de/en/research-networksfor-health-innovations-in-sub-saharan-africa-8690.php)

- European and Developing Countries Clinical Trials Partnership: clinical research to accelerate the development of new or improved drugs, vaccines, microbicides and diagnostics against HIV/AIDS, tuberculosis and malaria as well as other poverty-related infectious diseases in subSaharan Africa, with a focus on phase II and III clinical trials (http://www.edctp.org)

\section{Bundesministerium für Gesundheit; Federal Minstry of Health} (BMG):

Global Health Protection Programme: the main focus is supporting partner countries and the WHO in epidemic prevention measures (https://ghpp.de/en/).

\section{Bundesministerium für wirtschaftliche Zusammenarbeit und Entwicklung; Federal Ministry of Economic Cooperation and Development (BMZ):}

Hospital Partnerships: supports health partnerships worldwide but most are between German and African organizations. The range of focal themes covered encompasses mental health, nursing, oncology, ehealth, gynaecology and midwifery, ophthalmology, paediatrics, orthopaedics, surgery and dental health. The focus is on peer-to-peer partnerships for mutual learning (http://www.klinikpartnerschaften.de/en)

\section{Deutsche Forschungsgemeinschaft; German Research Foundation (DFG):}

African Cooperation Projects in Infectiology: joint research projects between scientists in Germany and Africa investigating infectious diseases and their social and societal implications. The DFG primarily seeks to encourage researchers in human and veterinary medicine to apply for funding of projects on the investigation of neglected tropical infectious diseases (https:// www.dfg.de/en/research_funding/announcements_ proposals/2017/info_wissenschaft_17_37/)

\section{Mainly non-clinical, public health oriented funding programmes:}

Deutscher Akademischer Austauschdienst;

German Academic Exchange Service (DAAD):

Partnerships for the Health Sector in Developing Countries: aims to offer medical training and further education opportunities in the medical field for partner universities, which are cutting-edge and suit the local context (https://www. daad.de/der-daad/unsere-aufgaben/entwicklungszusammen arbeit/foerderprogramme/hochschulen/infos/en/44500-pagelpartnerships-for-the-health-sector-in-developing-countries/) 
Partly social science oriented funding programmes: Deutsche Forschungsgemeinschaft; German Research Foundation (DFG):

German-African Cooperation Projects in Infectiology (see description among clinically oriented funding programmes)

\section{Open to clinical, public health and social science oriented funding programmes: \\ Volkswagen Foundation:}

Knowledge for Tomorrow - Cooperative Research Projects in Sub-Saharan Africa: Funding for symposia, workshops and summer schools, not only for health but thematically open (https://www.volkswagenstiftung.de/en/funding/our-fund ing-portfolio-at-a-glance/knowledge-for-tomorrow$\%$ E2\%80\%93-cooperative-research-projects-in-sub-saharanafrica)

Unsurprisingly, most Governmental initiatives are mainly clinically oriented including some which also support kinds of public health education and research. Social scientists can only apply for German-African Cooperation Projects in Infectiology at the Deutsche Forschungsgemeinschaft (DFG) which is next to clinical research also targeting social science research in the field. However, so far almost all funded projects have been clinically oriented.

How global health research by social scientists can contribute to a complex understanding of health problems can be illustrated by a research project on barriers to breast cancer care in Mali led by the author (Grosse Frie et al., 2018; 2019): Epidemiological and more clinically oriented studies had shown that in Mali and other sub-Saharan African countries the mortality rate for breast cancer patients is very high, and that this is related to late stage diagnosis. Education campaigns targeting the female population and health care professionals were commonly recommended to improve on prompt healthcare seeking and timely referral. By using qualitative and quantitative social science research methods the trajectories of breast care patients in Mali were analysed. High costs of cancer diagnosis and treatment and financial constraints on the individual and national level were identified as main barriers for survival and for receiving and providing adequate care. Therefore, solutions need to consider how to cover the costs of cancer care for Malian patients and, even more importantly, initiatives of the global community are needed that allow countries such as Mali to access and provide necessary drugs and technologies for adequate cancer care. Those factors on the meta- and macro-level need to be targeted by global health programmes and initiatives before implementing awareness and early detection programmes for breast cancer (Grosse Frie et al., 2018).

Social science based global health research focusing on determinants of health at different levels, as well as the interconnection between these levels, are rarely conducted, although such analyses could guide Germany and the international community in providing sustainable solutions for global developments in health and healthcare as formulated in die SDG 3 of the Agenda 2030. The integration of such research in German-African cooperation programmes in health education could also encourage African scientists in conducting global health research to integrate their perspectives and analyses in scientific discussions. This could also help African countries to demand international solutions that are necessary to improve the health and healthcare in their countries.

\section{Conclusions}

This paper described Germany's Global Health Strategy and Africa Strategy, which show that both global health and Africa have become increasingly important for international cooperation. It has been described that global health is strongly related to international and transnational aspects of health and therefore requires interdisciplinary and, in particular, social science approaches in global health teaching and research.

An important aspect of cooperation with Africa in the health sector is the education and training of health professionals, on the one hand to improve the shortcomings of skilled personnel in Africa, but, on the other hand, also to be able to possibly counteract the shortage of skilled health professionals in Germany. German-African cooperation in the education and training of health professionals serves different aspects such as aid, exchange and trade. Further research could pay more attention to different motives and formats of cooperation in the global health sector such as pharmaceutical or medical technology business motives in exporting models of medical schools and health trainings, or increasing the donor country's image and diplomatic status by means of donations to alleviate health crises or sponsoring joint high potential research projects.

While social science aspects are already included in the training of doctors and nurses in the curricula in Germany to meet the demands of the local health care market, they have so far not been taken into account in the more clinically oriented cooperation with Africa in the field of health education and training. This might be due to the fact that the participation of social scientists in the global health teaching and research in German medical university departments is still absent, and the current institutional funding for German-African cooperation in health education and research is still mainly clinically oriented.

It was argued that the involvement of social scientists in global health education and research in Germany needs to be fostered because of two reasons: firstly, to analyse determinants for global health inequalities with social science methods in order to offer solutions that can be considered in the German and international global health agenda and programmes; secondly, to ensure that in future social science modules are integrated into German-African cooperation programmes on health education and research. It would provide African health professionals with the necessary skills that provide leadership to their health systems. And since global health research also needs the African perspective, social science research on global health might empower African countries to point to (international) solutions needed for the health of their population and to bring determinants of health inequalities on the international political agenda. 


\section{Notes}

1 The following article is based on the paper which I presented at the VAD (German Association of African Studies) international conference at the University of Leipzig in June 2018, when I was affiliated to the Martin-Luther University Halle-Wittenberg as a research fellow.

\section{References}

Adick, C. (2019). German Higher Education Cooperation in Africa between Aid and Trade. Zeitschrift für internationale Bildungsforschung und Entwicklungspädagogik, 42(2), S. 4-10.

Bozorgmehr, K. (2010). Rethinking the 'global' in global health: a dialectic approach. Global Health, (6),1-19. [https://doi.org/10.1186/1744-8603-6-19]

Bundesärztekammer (2017). Ausländische Ärztinnen und Ärzte. Access on 07.05.2019 https://www.bundesaerztekammer.de/ueber-uns/aerztestatistik/aerzte statistik-2017/auslaendische-aerztinnen-und-aerzte/

Bundesgesundheitsministerium (BMG) (2013). Shaping Global Health. Taking Joint Action. Embracing Responsibility. The Federal Government's Strategy Paper. Berlin.

Bundesministerium für wirtschaftliche Zusammenarbeit und Entwicklung (BMZ) (2017). Marshall Plan with Africa. Health, education and social protection. Access on 07.05.2019 http://www.bmz.de/en/countries_regions/marshall_plan_with_africa/ contents/chapter_04/04/index.html

Bundesministerium für wirtschaftliche Zusammenarbeit und Entwicklung (BMZ) (2019). Globale Gesundheit. Eine Investition in die Zukunft. Bonn.

Bundesministerium für Wirtschaft und Energie (BMWi) (2017). Konzept „Pro! Afrika" Perspektiven fördern, Chancen nutzen, Wirtschaft stärken. Access on 28.04.2019 https://www.bmwi.de/Redaktion/DE/Downloads/S-T/strategiepa pier-pro-afrika.pdf

Connell, J., Zurn, P., Stilwell, B., Awases, M., \& Braichet, J. M. (2007). Sub-Saharan Africa: Beyond the health worker migration crisis? Social Sciences \& Medicine, 64(9),1876-1891.

Duvivier, R. J., Boulet, J. R., Opalek, A., van Zanten, M., \& Norcini, J. (2014). Overview of the world's medical schools: an update. Medical Education in Review, 48(9), 860-869. [https: //doi.org/10.1111/medu.12499]

Frenk, J., Chen, L., Bhutta, Z. A., Cohen, J., Crisp, N., Evans, T., Fineberg, H., Garcia, P., Ke, Y., Kelley, P., Kistnasamy, B., Meleis, A., Naylor, D., Pablos-Mendez, A., Reddy, S., Scrimshaw, S., Sepulveda, J., Serwadda, D., \& Zurayk, H (2010). Health professionals for a new century: transforming education to strengthen health systems in an interdependent world. The Lancet, 376(9756), 1923-1958.

Gesellschaft für Internationale Zusammenarbeit (GIZ) (2018). When everyone's a winner - international nurses for Germany. Access on 07.05.2019 https://www.giz. de/en/workingwithgiz/11666.html

Grosse Frie, K., Kamaté, B., Traoré, C. B., Ly, M., Mallé, B., Coulibaly, B., Wienke, A., \& Kantelhardt, E. J. (2018). Factors associated with time to first healthcare visit, diagnosis and treatment, and their impact on survival among breast cancer patients in Mali. PLoS One, 13(11). [https://doi.org/10.1371/journal.pone.0207928]

Grosse Frie, K., Kamaté, B., Traoré, C. B., Coulibaly, B., Mallé, B., \& Kantelhardt, E. J. (2019). Health system organisation and patient pathways: breast care patients' trajectories and medical doctors' practice in Mali. BMC Public Health, 19(1), 204. [https://doi: 10.1186/s12889-019-6532-8]

Havemann, M., \& Bösner, S. (2018). Global Health as „umbrella term“ - a qualitative study among Global Health teachers in German medical education. Global Health, 14(1), 1988-1996. [https://doi.org/10.1186/s12992-018-0352-y]

Kickbusch, .I (2006). The need for a European strategy on global health. Scandinavian Journal of Public Health, 34(6), 561-565.

Kickbusch, I., Franz, C., Holzscheiter, A., Hunger, I., Jahn, A., Köhler, C., Razum, O., \& Schmidt, J. O. (2017). Germany's expanding role in global health. The Lancet. Series: Germany and health, 390(10097), 898-912. [https://doi.org/10.1016/ S0140-6736(17)31460-5]

Koplan, J. P., Bond, T. C., Merson, M. H., Reddy, K. S., Rodriguez, M. H., Sewankambo, N. K., \& Wasserheit, J. N. (2009). Towards a common definition of global health. The Lancet, 373(9679), 1993-1995. [https://doi.org/10.1016/S01406736(09)60332-9]

Willcox, M. L., Peersman, W., Daou, P., Diakité, C. Bajunirwe, F., Mubangizi, V., Mahmoud. E. H., Moosa, S., Phaladze, N., Nkomazana, O., Khogali, M., Diallo, D., Maeseneer, J. de, \& Mant, D. (2015). Human resources for primary health care in sub-Saharan Africa: progress or stagnation. Human Ressources for Health, 13(76). [https://doi.org/10.1186/s12960-015-0073-8]

World Bank (2008). The business of health in Africa: partnering with the private sector to improve people's lives. International Finance Corporation. Washington, DC: World Bank.

World Health Organization (WHO) (2018). Global Health Observatory data repository. Access on 01.06.2018 https:/www.who.int/gho/health_workforce/en/

\section{Dr. Kristin Grosse Frie}

holds a Doctorate (Dr. phil.) in Sociology and has worked at German university hospital and research institutes on social determinants of health and health services. After a research visit at the London School of Hygiene and Tropical Medicine, she worked as a social scientist for the WHO (World Health Organisation) in Lyon. From 2015 - 2016 she conducted a research project in Mali as part of her DAAD scholarship (German Academic Exchange Service) in cooperation with the Institute of Medical Epidemiology, Biometrics and Informatics at the Martin-Luther-University Halle-Wittenberg. Meanwhile she holds the post of advisor at the "Deutsche Gesellschaft für Internationale Zusammenarbeit” (GIZ) in the programme University and Hospital Partnerships with Africa. 